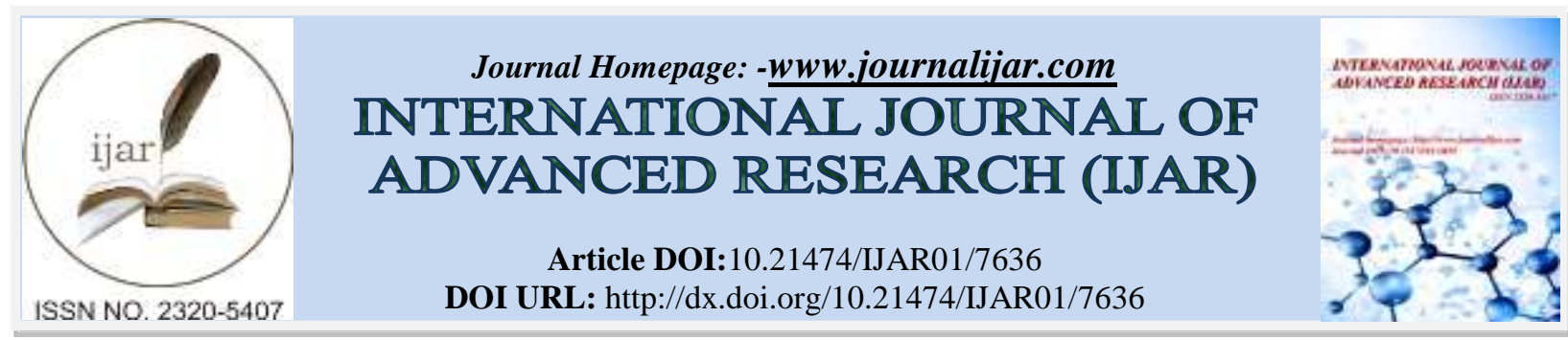

RESEARCH ARTICLE

\title{
SCIENTIFICALLY PRACTICED INTERVENTIONS FOR AUTISM SPECTRUM DISORDER.
}

\author{
Rajesh Ramachandran and Dr. J. Sujatha Malini. \\ Research Scholar, Assoc. Prof \& Head Dept. of Special Education \& Rehabilitation Science, Alagappa University, \\ Karaikudi, Tamil Nadu.
}

\section{Manuscript Info}

Manuscript History

Received: 24 June 2018

Final Accepted: 26 July 2018

Published: August 2018

Keywords:-

Autism Spectrum Disorder, Intervention.

\section{Abstract}

Autism is a complex neurological disorder that affects the functioning of the brain which means that it is a lifelong developmental disability that prevents people from understanding what they see, hear and otherwise sense. This results in severe problems with social relationships, communication and behaviour. Symptoms of Autism can be present in a variety of combinations and may be accompanying with other disabilities. There are many intervention strategies propounded but some of them lack scientific evidence which is adverse. This article tries to elucidate the most common effective scientifically tested intervention strategies for Autism Spectrum Disorder.

Copy Right, IJAR, 2018,. All rights reserved.

\section{Introduction:-}

Autism came from the Greek word AUTOS meaning self. During the year 1943, after studying behaviour of 11 children who came to the clinic Dr. Leo Kanner published a paper titled "Autistic Disturbances of Affective Contact" and described them as Autism. Though Kanner's paper was not keen on focussing the intervention aspects but over the years with many identifying Autism and need for intervention, many strategies evolved. Similarly, Dr Hans Asperger described similar condition as that of Kanner which later on became Asperger syndrome.

Autism is a complex neurological disorder generally affecting the communication, socialization and repetitive and stereotypic behaviours. Autism is a lifelong developmental disability can be seen in a variety of combinations and may be present with other disabilities. It is often accompanied by learning difficulties, severe sensory defensiveness, motor co-ordination difficulties, intellectual impairment, limitation in adaptive behaviours and seizure disorder.

Autism results in qualitative impairment, which means skills, are present in persons being diagnosed with Autism, they are not completely absent, but these skills do not develop appropriately according to the age.

Autism as defined by the $\mathbf{D S M}-\mathbf{I V}$ - TR (APA, 2000) which puts autism under Pervasive Developmental disorder are "characterised by severe and pervasive impairment in several areas of development: reciprocal social interaction skills, communication skills or the presence of stereotyped behaviours, interests and activities".

The latest prevalence of Autism is 1 in 59 as estimated by CDC which is higher than the earlier estimate of 1 in 68, which means that Autism is on the rise? CDC believes that the rise in estimates probably is due to improved identification of the condition. 
So rehabilitation of an individual using scientifically based intervention strategies is a necessity. Though there are many interventions coming up, for that matter if you search in Google about interventions in Autism, there are many but lack support from the scientific fraternity. In fact, due to the use of non-scientific interventions growth of the effective scientific based interventions for individuals having Autism is getting impeded. Parents and professionals to some extent find it very difficult to acknowledge or form an opinion about the scientific validity of the intervention to be used for individuals with Autism (Simpson, R.L 2005). Those families who are having children with autism will interpret the severity of the condition and impact of the same onto the individual and family as well. The families feel a very strong desire of an important development in finding a cure to the condition (Weiss, $\boldsymbol{M} \boldsymbol{J}$ et.al 2001, 2005).

Current research demonstrates that ASDs are due to alterations in brain functioningin other words they are brainbased disorders (Wass, 2011). Nonetheless a great deal of recent research indicates that early brain development is a dynamic process in which brain growth and development are intimately related to environmental stimulation.

\section{Review of Literature}

Reviewing literature is important as it substantiates the current knowledge and findings in relation to the study, the review here substantiates the fact that scientifically proven intervention strategies are more beneficial for any disorder or condition

Hoyson, M et.al (1984) in the study onIndividualized Group Instruction of Normally Developing and Autistic-like Children: The LEAP Curriculum Model evaluated 16 neurotypical children and 6 children diagnosed with ASD. The result indicated that children with ASD showed improved performance as compared to the neurotypical children attending the LEAP programme.

Pierce, K., \&Schreibman, L. (1995) in their study on Effects of peer-implemented pivotal response training in increasing complex social behaviours in children with autism, reported two children with autism who were taught to engage in a variety of social behaviours using peer-implemented pivotal response training. After the intervention, both children with autism maintained prolonged interactions with the peer and initiated play and conversations, along with increased engagement in language and joint attention behaviours. In addition to learning the same, teachers reported positive changes in social behaviour, with improvement in peer-preferred social behaviour.

Van Bourgondien ME, Reichle NC, Schopler E. (2003)Effects of Model treatment approach on adults with Autism, the study evaluated the effectiveness of a residential program, based on the TEACCH model, the results indicated that participants in the Carolina Living and Learning Centre experienced an increase in structure and individualized programming in the areas of communication, independence, socialization, developmental planning, and positive behaviour management.

Mary Jane Weiss, Kate Fiske\&SuzannahFerraioli (2008) in their article on Evidence based practices for Autism spectrum disorder highlighted that Applied Behaviour Analysis (ABA) has greater facts supporting the effectiveness of intervention in Autism. They also mentioned that evidence exists for the Lovaas/UCLA comprehensive treatment package, but more scientific evidences are required to support this intervention strategy.

Panerai, S., et.al (2009) reported that the TEACCH PROGRAMME assists learning with the use of structured and continuous intervention, environmental adaptations and alternative communication training for children with Autism Spectrum Disorder.

Beth A. Pfeiffer, et.al (2011) carried out a randomised controlled trail research to identify the effectiveness of sensory integration interventions in children diagnosed with ASD. Randomly children aged 6-12 having ASD were given sensory intervention and the results showed significant positive changes. The intervention also reduced problem behaviours among children.

Al zyoudi, Mohammed; et.al (2016) evaluated the effectiveness of using a social story intervention in order to bring changes in the social interaction skills among three students having children between the age range of 7-8 years with autism. The intervention comprised of reading social story and expecting answers to the questions being asked. The results indicated improvement in social interaction for all children. 
Duifhuis, E. A et. al (2017) in their study on the effect of Pivotal Response Treatment in Children with Autism Spectrum Disorders: A Non-Randomized Study with a Blinded Outcome Measure found out that children with ASD using PRT demonstrated significant improvement as compared to the individuals who were given treatment as usual.

\section{Intervention strategies}

There are many scientifically based intervention strategies but in this article the researchers have tried to focus on the most commonly used strategies The intervention strategies are divided into the following categories

\section{Interpersonal Relationship Interventions}

The scientifically based intervention practice under Interpersonal relationship are;

\section{Skill Based Interventions}

Applied Behaviour Analysis (ABA): ABA is based on the principles of learning (operant and classical conditioning). ABA using the principles of learning is to bring positive and meaningful changes in behaviour of an individual, which means that the skill behaviour is increased and reduction of problem behaviour. Behaviours are basically actions or skills which can be observed and measured. Here the role of ABA comes into picture. The process in ABA is based on the functional analysis of Antecedent (A) Behaviour (B) and Consequence (C), i.e. what precedes behaviour and what happens after the behaviour has occurred. The American Psychological Association (APA) has confirmed that ABA is an Evidence based intervention programme.

In ABA, the desired behaviour is increased through positive reinforcement, where in a child is rewarded for a desirable behaviour, this in future will increase the chances of that behaviour occurring again. Other forms are prompting, differential reinforcement, shaping and chaining.

\section{Pivotal Response teaching (PRT)}

PRT developed by Robert and Lynn Koegel. It is basically a child initiated play based intervention which has its roots from ABA. It is called Pivotal meaning crucially important aspectsin child development. Motivation, response to multiple cues, self-management and initiating social interactions are the crucial or pivotal areas which are targeted. Though it is mainly targeted to children but also helps adolescents and youth. The programme is designed in such a way that it meets the individual needs in home or school. The session consists of 6 segments wherein language, social skills and play skills are aimed through structured and unstructured social interactions.

\section{Discrete Trial Teaching (DTT)}

Ivar Lovaas and Robert Koegel developed DTT. It is a method which involves teaching tasks one at a time in a simple and organised manner. In this the individual skills are broken down and built up using discrete trail training. In DTT not all the skills are taught together but each step one by one. The steps being used in DTT is clearly defined and written in a structure form. DTT has 6 steps, they are antecedent, prompt, response, consequence for a correct response, consequence for an incorrect response and inter-trial interval

\section{Picture exchange communication system (PECS)}

PECS developed by Andy Bondy and Lori Frost is a distinctive alternative/augmentative communication system was used initially for pre-school students diagnosed with autism which later on was made available for learners of all ages having various cognitive, physical and communication difficulties. The principle of PECS is based on B F Skinner's Verbal behaviour wherein reinforcement and prompting techniques are used to teach communication skills among children. There are 6 phases of PECS, the individual is taught to communicate with pictures of the desired item.

\section{Structured teaching (TEACCH approach)}

Structured teaching is based on the TEACCH approach. TEACCH stands for Training and Education of Autistic and related communication- handicapped children developed by Eric Schopler at North Carolina. TEACCH approach is a promising intervention strategies with scientific evidences. The teaching strategies used in TEACHH approach is based on the influence of autism in the individual which affects the thinking, learning and behaviour. The Structured teaching has 5 elements; visual structure, routines and visual strategies, works systems, schedules and physical structure. 


\section{Cognitive interventions:- \\ Learning experiences:}

an alternative programme for pre-schoolers and parents (LEAP) designed in an inclusive set up generally has a clear vision of social development among children with ASD. In this programme children with Autism are taught alongside with the neurotypical. The curriculum in the LEAP programme is designed to focus on developing functional skills, independent play skills, social interaction, pre- academic skills, language skills and adaptive behaviour.

\section{Social Stories:}

Children with Autism face difficulties on every day when they come across different social situations which makes them anxious and confused. To overcome these Carol Gray developed a technique wherein the individuals are taught to communicate appropriately through short stories. These short stories are developed based on social situation which the child encounters. Social stories use descriptive, direct, perspective, affirmative, cooperative, control and partial sentences.

\section{Physiological/ Biological/ Neurological interventions: - Sensory Integration:}

Sensory Integration a neurobiological process is the ability to synthesize, organise and process the incoming sensory stimulation from the body and the environment in order to produce purposeful goal directed responses. Intervention in sensory integration focuses on the adaptive responses through appropriate activities and treatment methods. As per the online survey reported Sensory integration therapy is the third commonest treatment

\section{Conclusion:-}

The following intervention strategies mentioned in this article are the most commonly used, though there are more scientific or evidence based strategies not reaching many. In India structured teaching- TEACHH approach (Lal, Rubina, 2011), ABA is used quite commonly practiced. There are other strategies like Floor time, DTT, Augmentative and Alternative communication (AAC), PECS also used. National Institute for Empowerment of Persons with Multiple Disabilities (NIEPMD) also provides evidence based rehabilitation services to children having autism spectrum disorder. Structured Teaching- TEACHH and ABA is most commonly used strategy along with PECS and AAC.

The teachers must make a note of Scientifically practiced /Evidence based intervention strategies (EBIS), that scientifically practiced intervention is quite promising but we cannot ensure that it will be a successfor all children with ASD. The teachers should also understand that there is plenty of intervention strategies available and some of which have been shown to have research based evidence so the educators /teachers should carefully try to valid the intervention strategies available for proper usage among children with Autism Spectrum Disorder.

\section{References:-}

1. American Psychological Association (APA), 2000. Diagnostic and Statistical Manual of Mental Disorders, ed, 4

2. Al zyoudi, Mohammed; et.al (2016).The Effectiveness of Using a Social Story Intervention to Improve Social Interaction Skills of Students with Autism. Journal of the American Academy of Special Education Professionals, p17-30 Win 2016. https://eric.ed.gov/?q=social+stories+\&id=EJ1129718

3. Beth A. Pfeiffer, et.al (2011).Effectiveness of Sensory Integration Interventions in Children with Autism Spectrum Disorders: A Pilot Study. Am J Occup Ther. 2011 Jan-Feb; 65(1): 76-85.. https://www.ncbi.nlm.nih.gov/pmc/articles/PMC3708964/

4. Duifhuis, E. A et. al (2017),The effect of Pivotal Response Treatment in Children with Autism Spectrum Disorders: A Non-Randomized Study with a Blinded Outcome Measure. Journal of Autism and Developmental Disorders, v47 n2 p231-242 Feb 2017 retrieved from https://eric.ed.gov/?q=effect+of+PRT\&id=EJ1130169 on 13.8.18

5. Hoyson, M et.al (1984),Individualized Group Instruction of Normally Developing and Autistic-like Children: The LEAP Curriculum Model. Sage Journal Volume: 8 issue: 2, page(s): 157-172, Issue published: July 1, 1984. http://journals.sagepub.com/doi/10.1177/105381518400800209 retrieved on 13.8 .18

6. Lal, Rubina and Shahane, Anagha (2011) To determine the effect of TEACCH based intervention on development of independent work skills in children with autism. TEACCH Intervention for Autism, Autism 
Spectrum Disorders - From Genes to Environment, Prof. Tim Williams (Ed.), ISBN: 978-953-307-558-7, In Tech

7. Mary Jane Weiss, Kate Fiske\&SuzannahFerraioli (2008). Evidence based practice in Autism Spectrum Disorders in Clinical Assessment and Intervention for Autism Spectrum Disorders (Practical Resources for Mental Health Professionals) edited by Johnny Matson published by Elsevier London ISBN 978-0-12-373606-2

8. Panerai, S., et.al (2009). Special education versus inclusive education: the role of the TEACCH program. Journal of autism and developmental disorders, 39(6), 874-82.

9. Pierce, K., \&Schreibman, L. (1995). Increasing complex social behaviours in children with autism: Effects of peer-implemented pivotal response training. Journal of Applied Behaviour Analysis, 28, 285-295. Retrieved from https://www.ncbi.nlm.nih.gov/pmc/articles/PMC1279826/ on 1.3.2018)

10. Simpson, R.L 2005. Autism Spectrum Disorders- Interventions and treatments for Children and youth. Sage Publications India Pvt Ltd. ISBN: 978-81-7829-912-9

11. Van Bourgondien ME, Reichle NC, Schopler E. (2003) Effects of Model treatment approach on adults with Autism Journal of autism and developmental disorders, 2003 Apr;33(2):131-40.)

12. Weiss, M.J. (2001). Expanding ABA intervention in intensive programs for children with autism: The inclusion of natural environment training and fluency based instruction. The Behavior Analyst Today, 2, 182-187.

13. Weiss, M.J. (2005). Comprehensive ABA Programs: Integrating and evaluating the implementation of varied instructional approaches. Behavior Analyst Today, 6, 249-256.

14. https://autismguidelines.dmh.mo.gov/documents/Interventions.pdf

15. http://www.educateautism.com/applied-behaviour-analysis/discrete-trial-training.html retrieved on 13.8 .18

16. https://www.cdc.gov/media/releases/2018/p0426-autism-prevalence.html

17. http://www.researchautism.net/interventions/20/leap-and-autism retrieved on 13.8 .18

18. https://pecsusa.com/pecs/ retrieved on 14.8 .18

19. https://en.wikipedia.org/wiki/Literature_review.

20. https://www.iidc.indiana.edu/styles/iidc/defiles/IRCA/Structured\%20Teaching\%20Strategies\%20Article\%204.p df

21. https://www.special-learning.com/article/what_are_social_stories 